\title{
BMJ Open Suboptimal vitamin D status in Korean adolescents: a nationwide study on its prevalence, risk factors including cotinine-verified smoking status and association with atopic dermatitis and asthma
}

\author{
Eun Jung Byun, ${ }^{1}$ Jinyoung Heo, ${ }^{2}$ Sang Hyun Cho, ${ }^{1}$ Jeong Deuk Lee, ${ }^{1}$ \\ Hei Sung Kim ${ }^{1}$
}

To cite: Byun EJ, Heo J, Cho SH, et al. Suboptimal vitamin D status in Korean adolescents: a nationwide study on its prevalence, risk factors including cotinine-verified smoking status and association with atopic dermatitis and asthma. BMJ Open 2017;7:e016409. doi:10.1136/ bmjopen-2017-016409

- Prepublication history for this paper is available online. To view these files, please visit the journal online (http://dx.doi. org/10.1136/bmjopen-2017016409).

Received 12 February 2017 Revised 23 May 2017 Accepted 25 May 2017

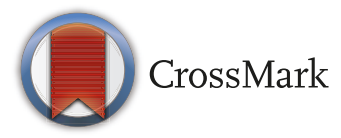

1Department of Dermatology, Incheon St. Mary's Hospital, College of Medicine, The Catholic University of Korea, Incheon, Republic of Korea ${ }^{2}$ Department of Preventive Medicine, The Catholic University of Korea, Seoul, Republic of Korea

Correspondence to Prof. Hei Sung Kim; hazelkimhoho@gmail.com

\section{ABSTRACT}

Objective To determine the prevalence and risk factors for suboptimal vitamin D status in Korean adolescents and to assess its relationship with atopic dermatitis (AD) and asthma at a national level.

Design This is a cross-sectional study with data from the Korean National Health and Nutrition Examination Survey. Information regarding socioeconomic characteristics, clinical data and environmental factors was collected. Blood and urine samples were taken for vitamin $D$ and cotinine, respectively. Descriptive and multivariable logistic regression was performed on the data.

Setting South Korea (nationwide).

Participants 2515 individuals aged $10-18$ years who participated in the Korean National Health and Nutrition Examination Survey from 2008 to 2011.

Main outcome measures Vitamin D status was determined through measurement of serum 25-hydroxyvitamin D (250HD). Smoking status was classified based on the urine cotinine level. Physician diagnosed with $A D$ and asthma were assessed using a questionnaire.

Results Overall, $73.3 \%$ of the subjects were vitamin D deficient $(250 \mathrm{HD}<20 \mathrm{ng} / \mathrm{mL})$ and $24.4 \%$ of the subjects were vitamin D insufficient (250HD, 20-29.9 ng/mL). Older age $(p<0.001)$, female gender $(p<0.001)$, urban residence $(p=0.019)$, higher body mass index $(p=0.003)$ and sampling in winter months (November-March) $(p<0.001)$ were independently associated with low serum $250 \mathrm{HD}$ levels. With cotinine verification, $18.2 \%$ of the participants were classified as active smokers, and $43.4 \%$ were classified as passive smokers. After adjusting for potential confounders, serum 250HD status showed no association with $A D$ or asthma.

Conclusion Vitamin $\mathrm{D}$ deficiency is highly prevalent in Korean adolescents. Cotinine-verified prevalence of smoking was also high, but its relationship with vitamin $D$ deficiency was not confirmed in our study. Above all, our results provide epidemiological evidence against the association of vitamin $D$ status with $A D$ and asthma at the national level among Korean adolescents.
Strengths and limitations of this study

- The strength of this study is that a nationally representative sample was used as the study population.

- This study is unique in that a cotinine-verified smoking status was adopted. Cotinine (a metabolite of nicotine) is a specific marker of smoking with high sensitivity.

- The limitation of the study is its cross-sectional design and the lack of data on the population's dietary and supplemental vitamin D intake. Also, the study has recall bias because the diagnoses of allergic conditions (atopic dermatitis (AD) and asthma) were self-reported.

- The definition of asthma and $A D$ was physiciandiagnosed asthma and $A D$ which may have missed some children with symptomatic asthma and $A D$ who have not been diagnosed.

\section{INTRODUCTION}

Vitamin D is essential for skeletal health and bone growth and its deficiency has been associated with skeletal deformities in children and fracture risk in adults. Recent studies have also identified the previously unanticipated roles of vitamin $\mathrm{D}$ in the immune system, cardiovascular system and cancer prevention. ${ }^{12}$ Despite growing health concerns over low vitamin D status, few nationwide studies have been performed to evaluate vitamin D deficiency in the Korean paediatric population. ${ }^{34}$ Suboptimal vitamin D level was reported in $70 \%$ of the US children $(9 \%$ vitamin $\mathrm{D}$ deficient, $61 \%$ vitamin $\mathrm{D}$ insufficient), ${ }^{5}$ and it was found in $41.7 \%$ of the children from New Zealand. ${ }^{6}$ Korean adolescents are theoretically at increased 
risk for vitamin $\mathrm{D}$ deficiency because of the high latitude $\left(34-38^{\circ} \mathrm{N}\right)$, culturally vigorous sun protection, reduced outdoor activity and lack of vitamin D-fortified food.

The increasing prevalence of allergic diseases is a worldwide phenomenon and it is strikingly more evident in the younger population compared with adults. ${ }^{7}$ Vitamin D has immunomodulatory functions, and its relationship with allergic disease has been evaluated in a number of studies. ${ }^{8-15}$ While some authors have reported about the protective role of vitamin $\mathrm{D}$ in atopic dermatitis $(\mathrm{AD})$, asthma, allergic rhinitis and allergic sensitisation in childhood, other authors have shown a deleterious effect. Although the exact cause of such conflicting results is not known, racial difference may be a contributing factor. Unfortunately, nationwide studies on vitamin D and allergic disease are limited and are mostly from western countries.

In this study, we aimed to identify the prevalence and risk factors for vitamin D deficiency in Korean adolescents and to assess its relationship with $\mathrm{AD}$ and asthma at the national level. Cotinine-verified smoking status was adopted in this study.

\section{METHODS}

\section{Study population}

This study was based on data acquired from the Korean National Health and Nutrition Examination Survey (KNHANES), a survey conducted by the Korea Centers for Disease Control and Prevention to provide nationally representative and reliable statistical data regarding the health, behaviour associated with health, nutrition and food intake status of the Korean population. Data were collected from 2008 to 2011, which corresponds to the second and third year of KNHANES IV (2007-2009) and the first and second year of KNHANES V (2010-2012). The survey included a health interview, a nutritional survey, physical examination and blood and urine tests. The institutional review board at the Korea Centers for Disease Control and Prevention/Incheon St. Mary's Hospital, The Catholic University of Korea (IRB number: OC17ZESI0055) approved the protocol, and all participants and their parents signed informed consent forms.

Both KNHANES IV and V adopted the stratified multistage cluster sampling design by using the rolling-survey sampling method. The rolling sample collected each year is the probability sample representing the general Korean population, and it is homogeneous and independent of each other. In 2008, 2009, 2010 and 2011, a total of 37753 individuals were sampled. The study population was further limited to 4598 adolescents aged 10-18 years. Among the 4598 participants, we subsequently excluded the following participants: those whose serum 25-hydroxyvitamin D (25OHD) levels were not measured; those without urine cotinine levels; those who did not completely answer the questions regarding $\mathrm{AD}$ or asthma; those without body mass index (BMI) measurement and those who had a chronic disease that may affect vitamin
D metabolism. Finally, a total of 2515 participants (1314 males and 1201 females) were eligible for analysis.

\section{Study variables}

Blood samples were collected from the antecubital vein, refrigerated immediately, transported to the central testing facility in cold storage and analysed within 24 hours of sampling. Serum 25OHD levels were measured as described previously ${ }^{16}$ and categorised as sufficient $(\geq 30 \mathrm{ng} / \mathrm{mL})$, insufficient $(20-29.9 \mathrm{ng} / \mathrm{mL})$ or deficient $(<20 \mathrm{ng} / \mathrm{mL}){ }^{17}$

Factors were categorised to analyse the risk factors for vitamin D deficiency. Age and BMI were continuous variables while season of sampling was categorised into winter months (November-March) and summer months (AprilOctober).${ }^{18}$ The region of residence of each participant was grouped as follows: urban (Seoul, Gyeonggi, Busan, Daegu, Incheon, Gwangju, Daejeon and Ulsan) and rural (Gangwon, Chungbuk, Chungnam, Jeonbuk, Jeonnam, Gyeongbuk, Gyeongnam and Jeju). ${ }^{19}$ Monthly income was standardised according to the number of family members (monthly income/number of family members) and it was divided into the following four quartile groups: lowest, lower middle, higher middle and highest. Participants who performed moderate physical activity for more than 30 min per day on more than 5 days a week and/ or strenuous physical activity for more than $20 \mathrm{~min}$ per day on more than 3 days a week were assigned to the regular exercise group. Regular walking was designated as 'yes' for those who walked for more than $30 \mathrm{~min}$ per day on more than 5 days a week. ${ }^{19}$ Smoking status was divided into three groups based on the urine cotinine level, which are as follows: non-smokers $(<5 \mathrm{ng} / \mathrm{mL})$, passive smokers (secondhand smoking) $(5-100 \mathrm{ng} / \mathrm{mL})$ and active smokers $(>100 \mathrm{ng} / \mathrm{mL}) \cdot{ }^{19-21}$ Urine cotinine level was measured by chromatography mass spectrometry using the Perkin Elmer Clarus 600T (PerkinElmer, Turku, Finland). All data were measured in a standardised manner and reviewed by the central quality control centre.

The following question was used to assess physician-diagnosed AD in each participant: "Have you been diagnosed with $\mathrm{AD}$ by a doctor?" or "Have you been told by a doctor that (your child) had AD?" Physician-diagnosed asthma was also determined using similar questions.

\section{Statistical analysis}

Statistical analyses were performed using an SAS survey procedure V.9.2 (SAS Institute), and two-sided p values of less than 0.05 were considered statistically significant. To produce unbiased national estimates representing the general Korean population, we used KNHANES sample weights accounting for the complex sampling design to each participant.

To compare the mean serum 25OHD levels among categories of each possible predicting factor, Student's t-test or analysis of variance (ANOVA; followed by TukeyKramer for multiple comparison) was used. 
Univariate analysis was performed to evaluate the association of the possible predicting factors, $\mathrm{AD}$ and asthma with vitamin D deficiency. Participants' characteristics were described using means and standard errors for continuous variables and numbers and percentages for categorical variables. Here, the Student's t-test or ANOVA was used for comparing continuous variables, as appropriate, and Rao-Scott $\chi^{2}$ test was used for comparing categorical variables. Variables with a $p$ value $<0.05$ in univariate analyses were included in the multivariate regression model for exploring factors associated with serum 25OHD.

To estimate the mean serum 25OHD levels in participants with and without $\mathrm{AD}$ and asthma, we performed simple and multiple linear regression analyses using the generalised linear model for a complex survey design. The estimated means were calculated as follows: no adjustment for potential confounders and confounder adjustment for age, gender, region, BMI, smoking and season of sampling.

To estimate the ORs for $\mathrm{AD}$ and asthma according to quartiles of serum 25OHD levels, we conducted simple and multivariate logistic regression analyses by using the generalised linear model for a complex survey design. The ORs and $95 \%$ CIs were calculated in the following ways: no adjustment for potential confounders and confounder adjustment for age, gender, region, BMI, smoking and season of sampling.

\section{RESULTS}

\section{General characteristics}

A total of 2515 subjects (1314 males and 1201 females, age: $14.4 \pm 0.1$ years) were included in the study. Table 1 summarises the baseline data of the participants. The mean BMI of the study population was $20.9 \mathrm{~kg} / \mathrm{m}^{2}$ (SE: 0.1 ). Blood samples were drawn more frequently in AprilOctober (58.4\%) than in November-March (41.6\%). The urine cotinine-verified smoking statuses were as follows: active smoking $18.2 \%$, passive smoking $43.4 \%$ and non-smoking $38.4 \%$. The prevalence of $\mathrm{AD}$ and asthma in the study population were $10.6 \%$ and $4.1 \%$, respectively.

\section{Serum 250HD levels in the study population}

The mean concentration of serum 25OHD in the 2515 subjects was $16.7 \mathrm{ng} / \mathrm{mL}$ (SE: 0.2 ), with a range of 3.0 to $46.2 \mathrm{ng} / \mathrm{mL}$. Overall, 1843 subjects $(73.3 \%)$ were vitamin D deficient, 613 subjects $(24.4 \%)$ were vitamin D insufficient and 59 subjects (2.3\%) were vitamin sufficient (figure 1). Girls had a significantly lower mean serum $25 \mathrm{OHD}$ level than boys $(16.0 \pm 0.2 \mathrm{ng} / \mathrm{mL}$ vs $17.3 \pm 0.2 \mathrm{ng} /$ $\mathrm{mL}, \mathrm{p}<0.001)$, and subjects sampled in winter months (November-March) had lower serum 25OHD levels than those sampled in summer months (April-October) $(14.7 \pm 0.2 \mathrm{ng} / \mathrm{mL}$ vs $18.1 \pm 0.2 \mathrm{ng} / \mathrm{mL}, \mathrm{p}<0.001)$. Passive smoking (vs non-smoking) and urban residence (vs rural) were also associated with statistically lower serum 25OHD levels ( $\mathrm{p}=0.038$ and $\mathrm{p}=0.002$, respectively) (table 2 ).
Univariate and multivariate analyses of factors associated with serum 250HD

Univariate analysis revealed that age $(\mathrm{p}<0.001)$, gender $(\mathrm{p}=0.003)$, region of residence $(\mathrm{p}=0.011)$, season of sampling $(\mathrm{p}<0.001)$, BMI $(<0.001)$ and smoking status $(\mathrm{p}=0.008)$ were associated with vitamin $\mathrm{D}$ deficiency (table 1).

Multivariate linear regression analysis of serum 25OHD levels was performed using variables that had a $\mathrm{p}$ value $<0.05$ in univariate analyses. Older age $(\mathrm{p}<0.001)$, female gender $(\mathrm{p}<0.001)$, urban residence $(\mathrm{p}=0.019)$, higher BMI $(\mathrm{p}=0.003)$ and sampling in winter months (NovemberMarch $)(p<0.001)$ were independently associated with low serum 25OHD levels (table 3). Multivariate ordinal logistic regression analysis of serum 25OHD showed similar results (table 4).

\section{Relationship of serum 250HD with AD and asthma}

Univariate analysis demonstrated that vitamin $\mathrm{D}$ deficiency was not significantly associated with $\mathrm{AD}(\mathrm{p}=0.468)$ or asthma $(\mathrm{p}=0.538)$ (table 1$)$.

Multivariate logistic regression showed that vitamin D deficiency had no association with $\mathrm{AD}$ and asthma after adjusting for age, gender, region of residence, BMI, smoking and season of sampling. The adjusted OR for $\mathrm{AD}$ and asthma increased across categories of serum 25OHD (1.00 (reference) for $\geq 30 \mathrm{ng} / \mathrm{mL}, 1.14$ and 4.87 each for $20-29.9 \mathrm{ng} / \mathrm{mL}$, and 1.52 and 5.31, respectively for $<20 \mathrm{ng} / \mathrm{mL}$ ), but it was not statistically significant $(\mathrm{p}=0.8078(\mathrm{AD})$ and $\mathrm{p}=0.1360$ (asthma) for $20-29.9 \mathrm{ng}$ / $\mathrm{mL}$ and $\mathrm{p}=0.4271$ (AD) and $\mathrm{p}=0.1042$ (asthma) for $<20 \mathrm{ng} / \mathrm{mL}$ ) (table 5).

Univariate or multivariate analyses with serum 25OHD levels as a continuous variable showed similar results, regardless of the adjustment (table 6).

\section{DISCUSSION}

In our cross-sectional study of Korean adolescents, Vitamin D deficiency was very common, where the mean concentration of serum 25OHD was $16.7 \mathrm{ng} / \mathrm{mL}$ with $73.3 \%$ of the subjects being vitamin $\mathrm{D}$ deficient (serum $25 \mathrm{OHD}<20 \mathrm{ng} / \mathrm{mL}$ ). Potential explanations for this remarkably low vitamin D status observed in Korean children include, but are not limited to, pigmented skin (skin pigmentation is known the reduce the skin's production of vitamin D in East Asian populations), ${ }^{3}$ vigorous use of sunscreens and possibly dietary factors. The Dietary Reference Intakes for vitamin D from the Institute of Medicine (2010) and the American Academy of Pediatrics state that the adequate intake (AI) of vitamin D is $15 \mu \mathrm{g}$ /day for children. ${ }^{22}{ }^{23}$ However, in the Dietary Reference Intakes for vitamin D for Koreans published in 2010, the AI of vitamin $\mathrm{D}$ for children is claimed to be $5 \mu \mathrm{g}$ / day, ${ }^{24}$ which we feel is too low. Exposure to sunlight, specifically ultraviolet $B$ (UVB), leads to vitamin D synthesis in the skin, which provides most of the vitamin $\mathrm{D}$ requirement of an individual. In Korea (latitude: $34-38^{\circ} \mathrm{N}$ ), vitamin $\mathrm{D}$ is 


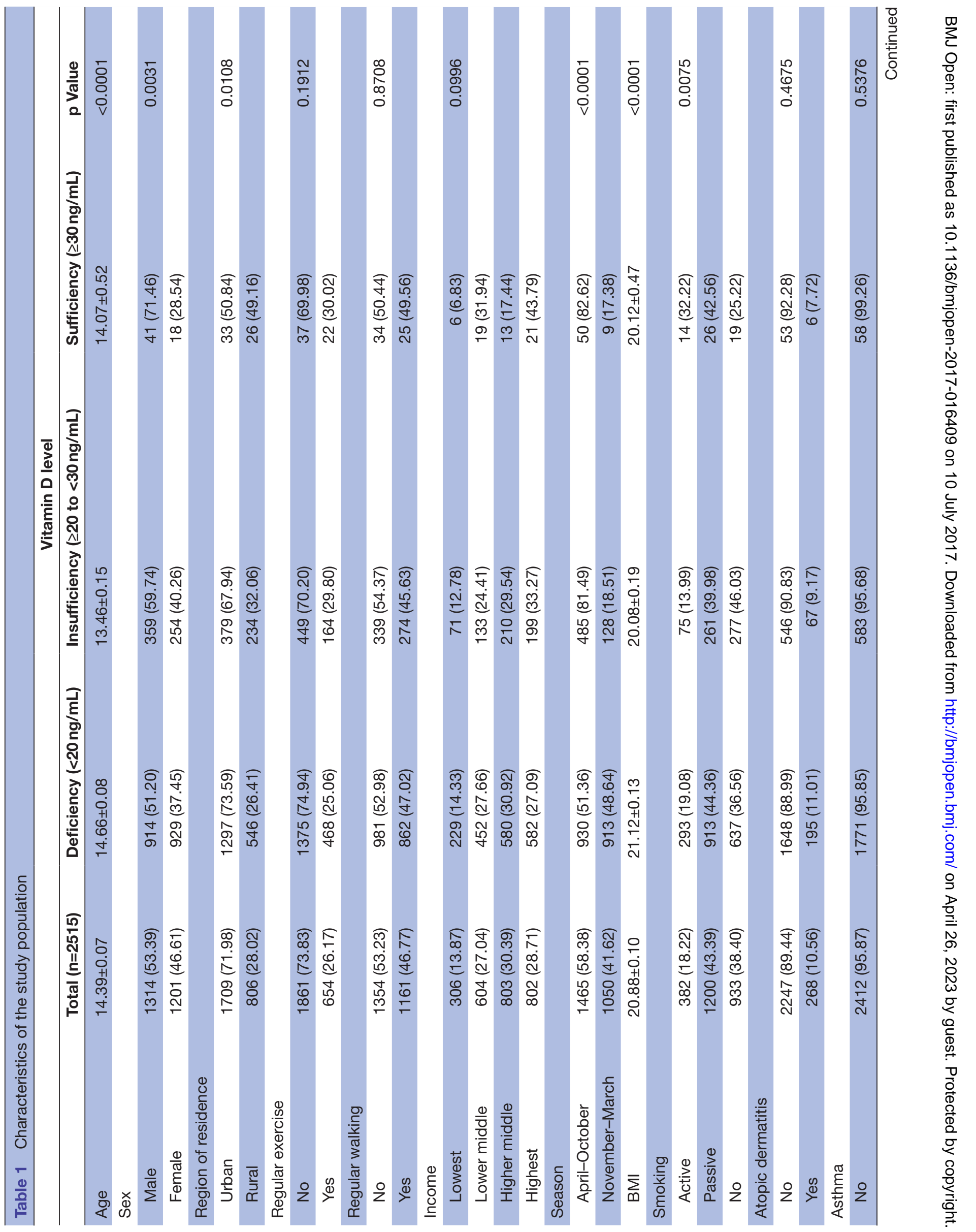



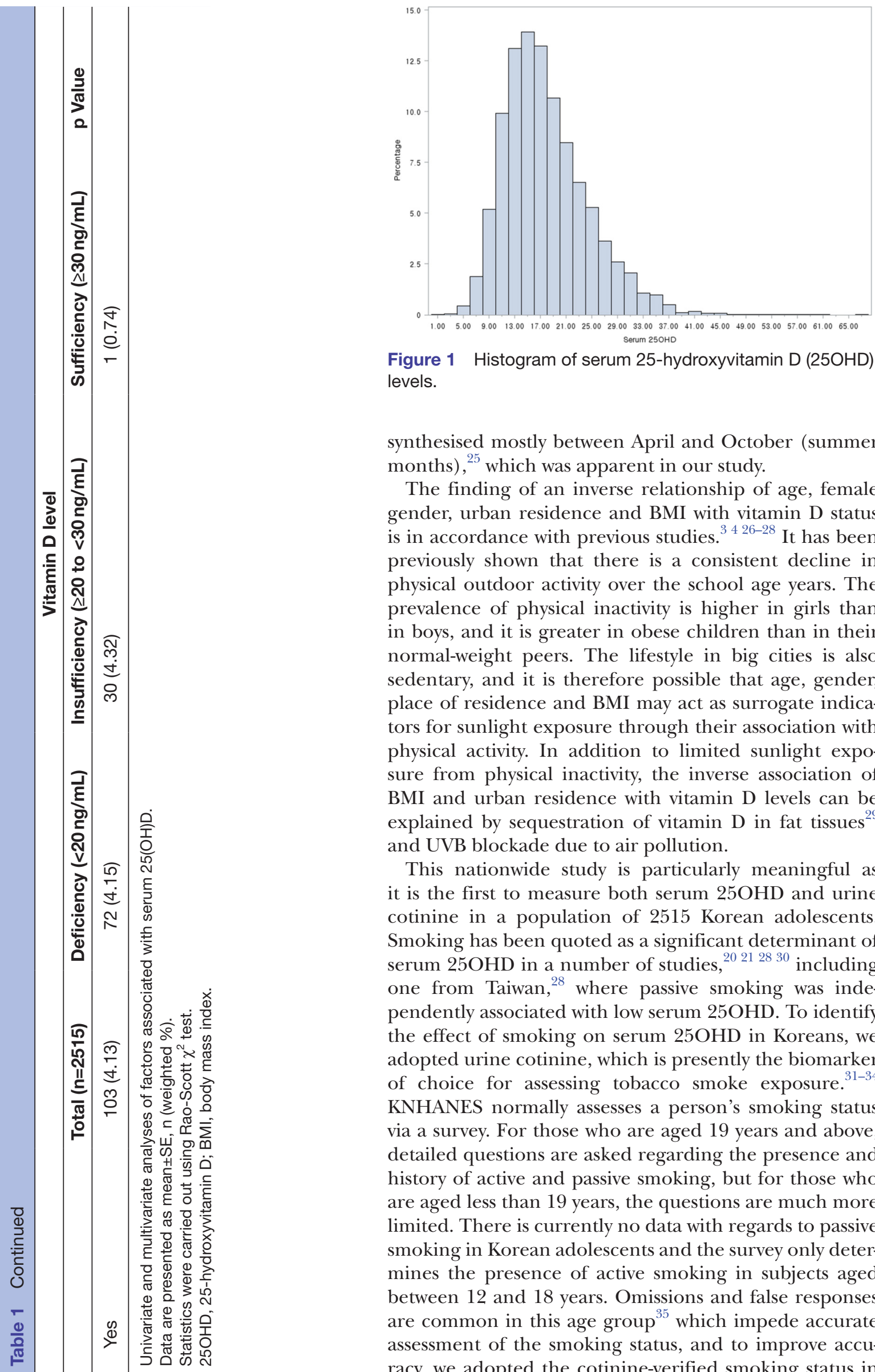

Figure 1 Histogram of serum 25-hydroxyvitamin D (25OHD) levels.

synthesised mostly between April and October (summer months), ${ }^{25}$ which was apparent in our study.

The finding of an inverse relationship of age, female gender, urban residence and BMI with vitamin $\mathrm{D}$ status is in accordance with previous studies. ${ }^{34}{ }^{46-28}$ It has been previously shown that there is a consistent decline in physical outdoor activity over the school age years. The prevalence of physical inactivity is higher in girls than in boys, and it is greater in obese children than in their normal-weight peers. The lifestyle in big cities is also sedentary, and it is therefore possible that age, gender, place of residence and BMI may act as surrogate indicators for sunlight exposure through their association with physical activity. In addition to limited sunlight exposure from physical inactivity, the inverse association of $\mathrm{BMI}$ and urban residence with vitamin $\mathrm{D}$ levels can be explained by sequestration of vitamin $\mathrm{D}$ in fat tissues ${ }^{29}$ and UVB blockade due to air pollution.

This nationwide study is particularly meaningful as it is the first to measure both serum 25OHD and urine cotinine in a population of 2515 Korean adolescents. Smoking has been quoted as a significant determinant of serum 25OHD in a number of studies, ${ }^{20} 212830$ including one from Taiwan, ${ }^{28}$ where passive smoking was independently associated with low serum 25OHD. To identify the effect of smoking on serum 25OHD in Koreans, we adopted urine cotinine, which is presently the biomarker of choice for assessing tobacco smoke exposure. ${ }^{31-34}$ KNHANES normally assesses a person's smoking status via a survey. For those who are aged 19 years and above, detailed questions are asked regarding the presence and history of active and passive smoking, but for those who are aged less than 19 years, the questions are much more limited. There is currently no data with regards to passive smoking in Korean adolescents and the survey only determines the presence of active smoking in subjects aged between 12 and 18 years. Omissions and false responses are common in this age group ${ }^{35}$ which impede accurate assessment of the smoking status, and to improve accuracy, we adopted the cotinine-verified smoking status in 
Table 2 Vitamin D levels in the study population

\section{Vitamin D $\mathrm{p}$ Value* $\mathrm{p}$ Value}

\begin{tabular}{lll}
\hline Total & $16.68 \pm 0.17$ \\
Sex & & \\
$\quad$ Male & $17.26 \pm 0.22<0.0001$ \\
\hline Female & $16.01 \pm 0.21$ & \\
Region of residence & & \\
Urban & $16.34 \pm 0.20$ & 0.0024 \\
Rural & $17.53 \pm 0.34$ & \\
\hline
\end{tabular}

Regular exercise

\begin{tabular}{|c|c|c|c|}
\hline No & $16.52 \pm 0.18$ & 0.0565 & \\
\hline Yes & $17.13 \pm 0.31$ & & \\
\hline \multicolumn{4}{|l|}{ Regular walking } \\
\hline No & $16.62 \pm 0.21$ & 0.687 & \\
\hline Yes & $16.74 \pm 0.24$ & & \\
\hline \multicolumn{4}{|l|}{ Income } \\
\hline Lowest & $16.09 \pm 0.41$ & 0.0043 & $\begin{array}{l}\text { Lowest versus } \\
\text { highest: } \\
0.0218\end{array}$ \\
\hline Lower middle & $16.63 \pm 0.29$ & & $\begin{array}{l}\text { Lower middle } \\
\text { versus } \\
\text { highest: } \\
0.1576\end{array}$ \\
\hline Higher middle & $16.47 \pm 0.24$ & & $\begin{array}{l}\text { Higher } \\
\text { middle versus } \\
\text { highest: } \\
0.0449\end{array}$ \\
\hline
\end{tabular}

Highest $\quad 17.22 \pm 0.31$

\begin{tabular}{|c|c|c|c|}
\hline \multicolumn{4}{|l|}{ Season } \\
\hline April-October & $18.11 \pm 0.21$ & $<0.0001$ & \\
\hline November-March & $14.67 \pm 0.21$ & & \\
\hline \multicolumn{4}{|l|}{ Smoking } \\
\hline Active & $16.52 \pm 0.42$ & 0.0062 & $\begin{array}{l}\text { Active versus } \\
\text { passive: } \\
0.9439\end{array}$ \\
\hline Passive & $16.37 \pm 0.23$ & & $\begin{array}{l}\text { Active versus } \\
\text { no: } 0.4260\end{array}$ \\
\hline No & $17.10 \pm 0.23$ & & $\begin{array}{l}\text { Passive } \\
\text { versus no: } \\
0.0382\end{array}$ \\
\hline
\end{tabular}

Atopic dermatitis

\begin{tabular}{ccc} 
No & $16.68 \pm 0.18$ & 0.8887 \\
\hline Yes & $16.63 \pm 0.32$ & \\
Asthma & & \\
No & $16.70 \pm 0.18$ & 0.4507 \\
Yes & $16.22 \pm 0.62$ & \\
\hline
\end{tabular}

Data are presented as mean \pm SE, $n$ (weighted \%).

* $p$ Value, t-test or analysis of variance (variables: income, smoking) result.

tp Value, multiple comparison: Tukey-Kramer.
Table 3 Multivariate linear regression analyses of serum $25 \mathrm{OHD}$ levels

\begin{tabular}{|c|c|c|c|}
\hline & Coefficient & $95 \% \mathrm{Cl}$ & p Value \\
\hline Age & -0.52 & -0.65 to -0.40 & $<0.0001$ \\
\hline \multicolumn{4}{|l|}{ Sex } \\
\hline Male & Reference & & $<0.0001$ \\
\hline Female & -1.40 & -1.88 to 0.91 & \\
\hline \multicolumn{4}{|c|}{ Region of residence } \\
\hline Urban & -0.85 & -1.55 to 0.14 & 0.0189 \\
\hline Rural & Reference & & \\
\hline $\mathrm{BMI}$ & -0.10 & -0.17 to 0.03 & 0.0034 \\
\hline \multicolumn{4}{|l|}{ Smoking } \\
\hline Active & 0.47 & -0.42 to 1.36 & 0.3017 \\
\hline Passive & -0.04 & -0.62 to 0.53 & 0.8842 \\
\hline No & Reference & & \\
\hline \multicolumn{4}{|l|}{ Season } \\
\hline April-October & Reference & & $<0.0001$ \\
\hline $\begin{array}{l}\text { November- } \\
\text { March }\end{array}$ & -3.38 & -3.97 to 2.79 & \\
\hline
\end{tabular}

Statistics were carried out using multivariable linear regression. Model: adjusted for age, sex, region, BMI, smoking, season. 25OHD, 25-hydroxyvitamin D; BMI, body mass index.

Table 4 Multivariate ordinal logistic regression analyses of categories of serum $25 \mathrm{OHD}$ levels

\begin{tabular}{|c|c|c|c|}
\hline & OR & $95 \% \mathrm{Cl}$ & p Value \\
\hline Age & 1.22 & 1.13 to 1.31 & $<0.0001$ \\
\hline \multicolumn{4}{|l|}{ Sex } \\
\hline Male & Reference & & 0.0002 \\
\hline Female & 1.68 & 1.28 to 2.21 & \\
\hline \multicolumn{4}{|l|}{ Region of residence } \\
\hline Urban & 1.32 & 0.96 to 1.81 & 0.0890 \\
\hline Rural & Reference & & \\
\hline BMI & 1.07 & 1.03 to 1.12 & 0.0011 \\
\hline \multicolumn{4}{|l|}{ Smoking } \\
\hline Active & 0.89 & 0.54 to 1.47 & 0.6539 \\
\hline Passive & 1.01 & 0.74 to 1.37 & 0.9535 \\
\hline No & Reference & & \\
\hline \multicolumn{4}{|l|}{ Season } \\
\hline April-October & Reference & & \\
\hline November-March & 4.49 & 3.25 to 6.22 & $<0.0001$ \\
\hline
\end{tabular}

Data are presented OR $(95 \% \mathrm{Cl})$.

Statistics were carried out using logistic regression.

Serum 250HD levels were categorised into three ordinal categories of vitamin D status ( $<20$ : deficiency, $\geq 20$ to $<30$ : insufficiency, $30 \geq$ : sufficiency).

Model: adjusted for age, sex, region, BMI, smoking, season.

25OHD, 25-hydroxyvitamin D; BMI, body mass index. 
Table 5 ORs and $95 \% \mathrm{Cls}$ of $\mathrm{AD}$ and asthma according to serum $25 \mathrm{OHD}$ levels

\begin{tabular}{|c|c|c|c|c|c|}
\hline & & \multicolumn{2}{|l|}{ Unadjusted } & \multicolumn{2}{|l|}{ Adjusted } \\
\hline & & OR (95\% Cl) & p Value & OR $(95 \% \mathrm{CI})$ & p Value \\
\hline \multirow[t]{3}{*}{$A D$} & Vitamin D Level & & & & \\
\hline & Insufficiency & 1.21 (0.43 to 3.39$)$ & 0.7228 & $1.14(0.41$ to 3.19$)$ & 0.8078 \\
\hline & Deficiency & $1.48(0.54$ to 4.02$)$ & 0.4441 & 1.52 (0.54 to 4.22$)$ & 0.4271 \\
\hline \multirow{3}{*}{ Asthma } & Sufficiency & Reference & & Reference & \\
\hline & Insufficiency & $6.02(0.75$ to 48.25$)$ & 0.0908 & $4.87(0.61$ to 39.05$)$ & 0.1360 \\
\hline & Deficiency & 5.79 (0.76 to 43.96$)$ & 0.0898 & $5.31(0.71$ to 39.86$)$ & 0.1042 \\
\hline
\end{tabular}

Data are presented OR $(95 \% \mathrm{Cl})$.

Statistics were carried out using logistic regression.

Adjusted for age, sex, region, BMI, smoking, season.

25OHD, 25-hydroxyvitamin D; AD, atopic dermatitis; BMI, body mass index.

our study. Urine cotinine level was measured for a limited time period (2008-2011), and this measurement has only been performed for those aged 10 years and above, which resulted in an inevitable reduction of our study population. We used a urine cotinine cut-off value of more than $100 \mathrm{ng} / \mathrm{mL}$ to discriminate smokers from non-smokers and $5 \mathrm{ng} / \mathrm{mL}$ as a threshold for non-smokers exposed to secondhand smoking based on published values. ${ }^{31-33}$ With cotinine verification, $18.2 \%$ of the participants were classified as active smokers, $43.4 \%$ of the participants were classified as passive smokers, and $38.4 \%$ of the participants were classified as non-smokers, where the percentage of smokers (active and passive) was higher than what we expected.

Smokers have been reported to have a significantly higher risk of vitamin D deficiency, ${ }^{20} 212830$ but this was not confirmed in our study. Since active smoking is usually done outdoors, this can result in greater exposure to sunlight which may alter the true effect of smoking on serum 25OHD. Passive smoking in adolescents is more likely to occur indoors and interestingly enough, passive smoking was reported to be independently associated with low serum 25OHD in Taiwanese children/adolescents. ${ }^{28}$ However, results can also be influenced by cotinine cut-off values and higher thresholds such as 10 or $30 \mathrm{ng} / \mathrm{mL}$ may be considered in the future when testing children as this population can have higher cotinine concentrations than adults due to differences in body distribution and nicotine metabolism. ${ }^{36}$

Some studies have indicated that an adequate concentration of vitamin $\mathrm{D}$ is protective against allergic disease in children. ${ }^{89153738}$ However, most of these findings have been reported in western countries and only a few studies have been performed in Asia. We consider our investigation meaningful because differences among ethnicities and subjects of various age groups can possibly affect the results.

In this national level study, the risk of $\mathrm{AD}$ and asthma were not dependent on serum 25OHD. The present study results, as well as prior studies which showed little association between vitamin $\mathrm{D}$ deficiency and $\mathrm{AD},{ }^{10-12} 28$ raise questions on the suggestion that vitamin $\mathrm{D}$ may be used to prevent or treat $\mathrm{AD}$. In fact, a Cochrane review found no evidence for an effect of vitamin $\mathrm{D}$ supplementation

Table 6 The estimated mean serum 25OHD levels and their differences according to AD and asthma

\begin{tabular}{cllllc}
\hline & Unadjusted & & & Adjusted \\
\hline & Estimated mean & $\begin{array}{l}\text { Difference } \\
\text { (estimated mean) }\end{array}$ & p Value & Estimated mean & $\begin{array}{l}\text { Difference } \\
\text { (estimated mean) }\end{array} \quad$ p Value \\
\hline AD & & & & $0.19 \pm 0.33$ \\
Yes & $16.68 \pm 0.18$ & $0.05 \pm 0.34$ & 0.8887 & $16.87 \pm 0.16$ & 0.5776 \\
No & $16.63 \pm 0.32$ & & & $16.68 \pm 0.32$ & $0.72 \pm 0.48$ \\
Asthma & & & & $16.88 \pm 0.15$ & 0.1313 \\
Yes & $16.70 \pm 0.18$ & $0.48 \pm 0.63$ & 0.4507 & $16.15 \pm 0.47$ & \\
\hline No & $16.22 \pm 0.62$ & & & & \\
\hline
\end{tabular}

Data are presented as numeric, mean \pm SD.

Statistics were carried out using simple linear regression and multivariable linear regression.

Adjusted for age, sex, region, BMI, smoking, season.

25OHD, 25-hydroxyvitamin D; AD, atopic dermatitis; BMI, body mass index. 
on $\mathrm{AD} .^{39}$ The beneficial effect of sunlight on $\mathrm{AD}$ has been well documented, but this is probably due to the anti-inflammatory and antimicrobial effects of UV and not those of vitamin $\mathrm{D}$.

As in $\mathrm{AD}$, there has been considerable controversy over the relationship between vitamin D levels and asthma in children. While some studies showed an inverse relationship between vitamin D levels and current wheeze and asthma severity, ${ }^{8}$ others such as Hollams et $a l^{40}$ showed no significant cross-sectional association between serum vitamin D levels and current asthma. Our study too did not find any relationship between vitamin $\mathrm{D}$ level and asthma, but further studies would be needed to determine a causal relationship and its mechanism.

This study has several notable strengths. The sampling of adolescents across a broad age range, a large sample size with robust data collection, incorporation of objective markers of smoking status, and a thorough analysis strengthen the results of this study. Limitations of the study include its cross-sectional design and lack of data on dietary and supplemental vitamin D intake. Also, the study is prone to recall bias because diagnoses of allergic conditions (AD and asthma) were self-reported. The definition of asthma and $\mathrm{AD}$ were physician-diagnosed asthma and $\mathrm{AD}$, which may have missed some children with symptomatic asthma and $\mathrm{AD}$ in the population who have not been diagnosed. Although season adjusted, deseasonalisation of vitamin D levels with an algorithm $^{41}$ may have further increased the accuracy and strength of our study.

In conclusion, a high prevalence of vitamin D deficiency was noted in Korean adolescents aged 10 to 18 years. For high-risk individuals of vitamin D deficiency, we suggest vitamin D supplementation and food fortification. Adequate outdoor activity should also be emphasised in Korean adolescents, especially high school students, via media promotion and public health plans by schools and government. We found no apparent association between the cotinine-verified smoking status, $\mathrm{AD}$ and asthma with vitamin D deficiency, which merits further study.

Contributors EJB, SHC, JDL and HSK made substantial contributions to the conception or design of the work. JYH and HSK had role in the acquisition, analysis and interpretation of data tor the work. EJB, SHC, JDL and HSK drafted and revised the work and all authors gave final approval and agreed to be accountable for all aspects of the work.

Funding This study was supported by a grant from the Korean Healthcare Technology R\&D project, Ministry of Health and Welfare, Republic of Korea (grant no HN15C0105).

Disclaimer The funders of this study had no role in study design, collection, analysis and interpretation of data, writing of the manuscript or decision to submit for publication.

\section{Competing interests None declared.}

Patient consent Detail has been removed from this case description/these case descriptions to ensure anonymity. The editors and reviewers have seen the detailed information available and are satisfied that the information backs up the case the authors are making.

Ethics approval The institutional review board at the Korea Centers for Disease Control and Prevention/Incheon St. Mary's Hospital, The Catholic University of Korea (IRB number: OC17ZESI0055) approved the protocol.
Provenance and peer review Not commissioned; externally peer reviewed.

Data sharing statement All data from the study, published and unpublished, are available with the principle investigators. The data are managed under the Department of Dermatology, Incheon St. Mary's Hospital, The Catholic University of Korea, Incheon, Korea.

Open Access This is an Open Access article distributed in accordance with the Creative Commons Attribution Non Commercial (CC BY-NC 4.0) license, which permits others to distribute, remix, adapt, build upon this work non-commercially, and license their derivative works on different terms, provided the original work is properly cited and the use is non-commercial. See: http://creativecommons.org/ licenses/by-nc/4.0/

(c) Article author(s) (or their employer(s) unless otherwise stated in the text of the article) 2017. All rights reserved. No commercial use is permitted unless otherwise expressly granted.

\section{REFERENCES}

1. Holick MF. Vitamin D deficiency. N Engl J Med Overseas Ed 2007;357:266-81.

2. Cheng HM, Kim S, Park GH, et al. Low vitamin D levels are associated with atopic dermatitis, but not allergic rhinitis, asthma, or IgE sensitization, in the adult Korean population. J Allergy Clin Immunol 2014;133:1048-55.

3. Kim SH, Oh MK, Namgung R, et al. Prevalence of 25-hydroxyvitamin $D$ deficiency in Korean adolescents: association with age, season and parental vitamin D status. Public Health Nutr 2014;17:122-30.

4. Lee YA, Kim HY, Hong H, et al. Risk factors for low vitamin D status in Korean adolescents: the Korea National Health and Nutrition Examination Survey (KNHANES) 2008-2009. Public Health Nutr 2014;17:764-71.

5. Kumar J, Muntner P, Kaskel FJ, et al. Prevalence and associations of 25-hydroxyvitamin D deficiency in US children: NHANES 2001-2004. Pediatrics 2009;124:e362-70.

6. Rockell JE, Green TJ, Skeaff CM, et al. Season and ethnicity are determinants of serum 25-hydroxyvitamin D concentrations in New Zealand children aged 5-14 y. J Nutr 2005;135:2602-8.

7. Asher MI, Montefort S, Bjorksten B, et al. Worldwide time trends in the prevalence of symptoms of asthma, allergic rhino-conjunctivitis, and eczema in childhood: ISAAC Phases one and three repeat multicountry cross-sectional surveys. Lancet 2006;26:733-43.

8. Bener A, Ehlayel MS, Tulic MK, et al. Vitamin D deficiency as a strong predictor of asthma in children. Int Arch Allergy Immunol 2012;157:168-75.

9. El Taieb MA, Fayed HM, Aly SS, et al. Assessment of serum 25-hydroxyvitamin D levels in children with atopic dermatitis: correlation with SCORAD index. Dermatitis 2013;24:296-301.

10. Berents TL, Lødrup Carlsen KC, Mowinckel P, et al. Vitamin D levels and atopic eczema in infancy and early childhood in Norway: a cohort study. Br J Dermatol 2016;175:95-101.

11. Barman $\mathrm{M}$, Jonsson $\mathrm{K}$, Hesselmar $\mathrm{B}$, et al. No association between allergy and current 25-hydroxy vitamin $D$ in serum or vitamin $D$ intake. Acta Paediatr 2015;104:405-13.

12. Chiu YE, Havens PL, Siegel DH, et al. Serum 25-hydroxyvitamin D concentration does not correlate with atopic dermatitis severity. J Am Acad Dermatol 2013;69:40-6.

13. Yang HK, Choi J, Kim WK, et al. The association between hypovitaminosis $\mathrm{D}$ and pediatric allergic diseases: a Korean nationwide population-based study. Allergy Asthma Proc 2016;37:64-9.

14. Lee SJ, Kang BH, Choi BS. Vitamin D serum levels in children with allergic and vasomotor rhinitis. Korean J Pediatr 2015;58:325-9.

15. Cheon BR, Shin JE, Kim YJ, et al. Relationship between serum 25-hydroxyvitamin D and interleukin-31 levels, and the severity of atopic dermatitis in children. Korean J Pediatr 2015;58:96-101.

16. Nam GE, Kim DH, Cho KH, et al. 25-Hydroxyvitamin D insufficiency is associated with cardiometabolic risk in Korean adolescents: the 2008-2009 Korea National Health and Nutrition Examination survey (KNHANES). Public Health Nutr 2014;17:186-94.

17. Holick MF, Binkley NC, Bischoff-Ferrari HA, et al. Evaluation, treatment, and prevention of vitamin $D$ deficiency: an Endocrine Society Clinical Practice guideline. J Clin Endocrinol Metab 2011;96:1911-30.

18. McKinney K, Breitkopf CR, Berenson AB. Association of race, body fat and season with vitamin $D$ status among young women: a crosssectional study. Clin Endocrinol 2008;69:535-41.

19. Choi HS, Oh HJ, Choi H, et al. Vitamin D insufficiency in Korea--a greater threat to younger generation: the Korea National Health and 
Nutrition Examination Survey (KNHANES) 2008. J Clin Endocrinol Metab 2011:96:643-51.

20. Kassi EN, Stavropoulos S, Kokkoris P, et al. Smoking is a significant determinant of low serum vitamin $D$ in young and middle-aged healthy males. Hormones 2015;14:245-50.

21. Manavi KR, Alston-Mills BP, Thompson MP, et al. Effect of serum cotinine on vitamin $D$ serum concentrations among american females with different ethnic backgrounds. Anticancer Res 2015;35:1211-8.

22. Wagner CL, Greer FR; American Academy of Pediatrics Section on BreastfeedingAmerican Academy of Pediatrics Committee on Nutrition. Prevention of rickets and vitamin $D$ deficiency in infants, children, and adolescents. Pediatrics 2008;122:1142-52.

23. Ross AC, Manson JE, Abrams SA, et al. The 2011 report on dietary reference intakes for calcium and vitamin $D$ from the institute of medicine: what clinicians needs to know. J Clin Endocrinol Metab 2011;96:53-8.

24. Ryoo E. Adolescent nutrition: what do pediatricians do? Korean $J$ Pediatr 2011;54:287-91.

25. Chung IH, Kim HJ, Chung S, et al. Vitamin D deficiency in Korean children: prevalence, risk factors, and the relationship with parathyroid hormone levels. Ann Pediatr Endocrinol Metab 2014;19:86-90.

26. Carpenter TO, Herreros F, Zhang JH, et al. Demographic, dietary, and biochemical determinants of vitamin $\mathrm{D}$ status in inner-city children. Am J Clin Nutr 2012;95:137-46.

27. Tolppanen AM, Fraser A, Fraser WD, et al. Risk factors for variation in 25-hydroxyvitamin $\mathrm{D} 3$ and $\mathrm{D}_{2}$ concentrations and vitamin $\mathrm{D}$ deficiency in children. J Clin Endocrinol Metab 2012;97:1202-10.

28. Yao TC, Tu YL, Chang SW, et al. Suboptimal vitamin D status in a population-based study of Asian children: prevalence and relation to allergic diseases and atopy. PLoS One 2014;9:e99105.

29. Wortsman J, Matsuoka LY, Chen TC, et al. Decreased bioavailability of vitamin D in obesity. Am J Clin Nutr 2000;72:690-3.

30. Cutillas-Marco E, Fuertes-Prosper A, Grant WB, et al. Vitamin $D$ deficiency in South Europe: effect of smoking and aging. Photodermatol Photoimmunol Photomed 2012;28:159-61.
31. Jeong BY, Lim MK, Yun EH, et al. Tolerance for and potential indicators of second-hand smoke exposure among nonsmokers: a comparison of self-reported and cotinine verified second-hand smoke exposure based on nationally representative data. Prev Med 2014;67:280-7.

32. Jung S, Lee IS, Kim SB, et al. Urine cotinine for assessing tobacco smoke exposure in Korea: analysis of the Korea National Health and Nutrition Examination survey (KNHANES). Tuberc Respir Dis 2012;73:210-8.

33. Florescu A, Ferrence R, Einarson T, et al. Methods for quantification of exposure to cigarette smoking and environmental tobacco smoke: focus on developmental toxicology. Ther Drug Monit 2009;31:14-30.

34. Kim Y, Choi YJ, Oh SW, Sw O, et al. Discrepancy between selfreported and urine-cotinine verified smoking status among Korean male adults: analysis of health check-up data from a single private hospital. Korean J Fam Med 2016;37:171-6.

35. Park MB, Nam EW, Lee SK, et al. The correlation of different cotinine levels with questionnaire results: a comparative study for different measurement methods of the adolescent smoking rate in Korea. Asia Pac J Public Health 2015;27:542-50.

36. Haufroid V, Lison D. Urinary cotinine as a tobacco-smoke exposure index: a minireview. Int Arch Occup Environ Health 1998;71:162-8.

37. Paul G, Brehm JM, Alcorn JF, et al. Vitamin D and asthma. Am J Respir Crit Care Med 2012;185:124-32.

38. Bozzetto S, Carraro S, Giordano G, et al. Asthma, allergy and respiratory infections: the vitamin D hypothesis. Allergy 2012;67:10-17.

39. Bath-Hextall FJ, Jenkinson C, Humphreys R, et al. Dietary supplements for established atopic eczema. Cochrane Database Syst Rev 2012;15:CD005205.

40. Hollams EM, Hart PH, Holt BJ, et al. Vitamin D and atopy and asthma phenotypes in children: a longitudinal cohort study. Eur Respir $J$ 2011;38:1320-7.

41. van der Mei IA, Ponsonby AL, Dwyer T, et al. Vitamin D levels in people with multiple sclerosis and community controls in Tasmania, Australia. J Neurol 2007;254:581-90. 